\title{
Author Spotlight: Sanchit Gupta
}

\section{Sanchit Gupta ${ }^{1}$}

Published online: 14 July 2020

(c) Springer Science+Business Media, LLC, part of Springer Nature 2020

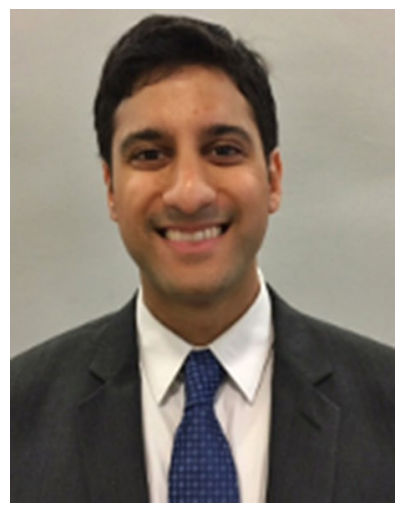

Sanchit Gupta, MD, MS, is a third-year gastroenterology fellow at Brigham and Women's Hospital. He completed his MD and Masters in Clinical Research at Albert Einstein College of Medicine and his internal medicine residency training at Mount Sinai Hospital. During his fellowship, Sanchit has participated in research in inflammatory bowel diseases and fecal microbiota transplantation, and has been an educator for multiple courses at Harvard Medical School. He will further his training as the Inflammatory Bowel Diseases fellow at Brigham and Women's starting in July 2021. He enjoys learning through research and education with his co-fellows tremendously and looks forward to continuing these endeavors in the future!

Publisher's Note Springer Nature remains neutral with regard to jurisdictional claims in published maps and institutional affiliations.
Sanchit Gupta

sgupta34@bwh.harvard.edu

1 Brigham and Women's Hospital, Boston, USA 